\title{
Reduced-order modeling and simulated annealing optimization for efficient residential building utility bill calibration ${ }^{\text {th }}$
}

\author{
Joseph J. Robertson ${ }^{\mathrm{a}, *}$, Ben J. Polly ${ }^{\mathrm{a}}$, Jon M. Collis ${ }^{\mathrm{b}}$ \\ ${ }^{a}$ Buildings and Thermal Systems Center, National Renewable Energy Laboratory, Golden, CO \\ ${ }^{b}$ Applied Mathematics and Statistics Department, Colorado School of Mines, Golden, CO
}

\begin{abstract}
This simulation study applies the general framework described in BESTEST-EX for self-testing residential building energy model calibration methods. The National Renewable Energy Laboratory's BEopt/DOE-2.2 is used to evaluate an automated regression metamodeling-based calibration approach in the context of monthly synthetic utility data for a 1960's-era existing home in a cooling-dominated climate. The home's model inputs are assigned probability distributions representing uncertainty ranges, pseudo-random selections are made from the uncertainty ranges to define "explicit" input values, and synthetic utility billing data are generated using the explicit input values. A central composite design is used to develop response surface statistical models for the home's predicted energy use. Applying a gradient-based simulated annealing optimization algorithm to the statistical "metamodels", the calibration approach systematically adjusts values of the design variables and reduces disagreement between predicted energy use and synthetic utility billing data. Various retrofit measures are applied and used to assess accuracy of retrofit savings predictions resulting from using the calibration procedure. Substituting actual BEopt/DOE-2.2 model simulations with the statistical models reduces overall calibration procedure run-time while sacrificing only a limited degree of accuracy for retrofit savings predictions.
\end{abstract}

Keywords: model calibration, numerical optimization, response surface methodology, residential building simulation

\section{Introduction}

Building energy simulation programs are often used to model the thermal performance of commercial and residential buildings, and more specifically, to recommend energy efficiency upgrade packages and operational strategies for existing buildings. Due to uncertainties in building energy model inputs, accurate model energy use predictions are not guaranteed. ${ }^{1}$ Modelers often apply calibration procedures involving input value adjustments to pre-retrofit building energy models; the goal is to reconcile software predictions and measured energy uses. The general assumption is that calibrating the building energy model increases the accuracy of energy savings predictions for retrofit measures.

Understanding how uncertainties in simulation software energy use predictions may be reduced is important to recommending and achieving the most effective energy efficiency upgrade packages and operational strategies for buildings. The potential for reduction of energy consumption in buildings is maximized when the most impactful retrofit packages and operational strategies are considered and applied. Building model calibration may provide an avenue for understanding and correcting the inaccuracies in building energy model inputs, thereby increasing energy savings prediction accuracy and confidence in the most potentially impactful retrofit packages and operational strategies.

\footnotetext{
This work was supported by the U.S. Department of Energy under Contract No. DE-AC36-08GO28308 with the National Renewable Energy Laboratory.

*Corresponding author. Tel: 303-275-4575. Address: 15013 Denver W Pkwy, MS ESIF200, Golden, CO, 80401.

Email addresses: joseph.robertson@nrel.gov (Joseph J. Robertson), ben.polly@nrel.gov (Ben J. Polly), jcollis@mines.edu (Jon M. Collis)

${ }^{1}$ Input uncertainty is not the only known source of prediction error.
} 
Current model calibration methods range in complexity from manual calibration based on user judgment to automated calibration based on analytical, numerical, and statistical methods [1-10]. Due to the underdetermined nature of the calibration problem (i.e., there can be many combinations of input parameters that will result in good agreement with utility billing data), calibration solutions based on manual adjustments and user judgment may differ. Reddy and Maor [11] recognize the need for consistency in model calibration techniques, stating in ASHRAE 1051-RP that model calibration generally has been regarded as more of an art than a science. Some detailed guidelines, suitable for calibrating commercial building energy models using systematic and mathematical approaches, have been established in ASHRAE 1051-RP. However, these guidelines may not be cost-effective for residential building applications due to their computational expense. For example one of the suggested components, a refined grid search, can require numerous time-consuming model simulations.

This research presents and tests two automated calibration techniques based on the general guidelines set forth in ASHRAE 1051-RP, but adapted for residential building applications. Both methods involve using an automated, nonlinear simulated annealing optimization routine to iteratively predict energy use for combinations of input parameters and search for a calibration solution that minimizes an objective function [12]. The second of the two modifies the first to reduce the computational expense associated with costly building energy model simulations through substitution with more computationally efficient response surface models.

To test the accuracy tradeoffs in using these calibration techniques, a self-testing procedure described in Building Energy Simulation Test for Existing Homes (BESTEST-EX) [13] is employed. The test procedure describes a method for using a single software tool to compare reference, calibrated, and uncalibrated simulation results (see "Performing Calibration Tests Without Using Reference Programs" [Appendix B] of Judkoff et al. [14]). This study uses the software tool BEopt/DOE-2.2 2 and two calibration methods to assess energy savings prediction accuracy for retrofit measures. Section 2 describes the self-testing procedure.

Whereas individual BEopt/DOE-2.2 simulations take seconds to complete, optimizations requiring several thousand model simulations can become time consuming and very costly. Response surface models help to alleviate these costs since they are able to predict energy use by using minimally expensive reduced-order models requiring only simple arithmetic calculations. Section 3 describes the implementation of the calibration methods.

\section{BESTEST-EX-Based Testing Methodology}

In this section, the approach used for evaluation of model calibration techniques is described. The approach is based on the self-testing procedure described in BESTEST-EX [13].

\subsection{Define Test House}

One 1960'-era all-electric ranch-style home, partly-based ${ }^{3}$ on BESTEST-EX Case L200EX-P, is considered in the analysis. The key pre-retrofit characteristics of the modeled house are given in Table 1.

\footnotetext{
${ }^{2}$ BEopt (Building Energy Optimization) is a residential building optimization tool developed by the National Renewable Energy Laboratory (NREL). See beopt.nrel.gov and Christensen et al. [15] for more information on BEopt.

${ }^{3}$ Including heating and cooling systems (which were not considered in BESTEST-EX) allowed easier modeling with BEopt and permitted the testing of equipment-related retrofits.
} 
Table 1: Characteristics of the modeled house.

\begin{tabular}{|c|c|}
\hline Category & Characteristics \\
\hline Location & Las Vegas, NV \\
\hline Orientation & Front of house faces South \\
\hline Dimensions & $\begin{array}{l}\mathrm{N} / \mathrm{S}=57 \mathrm{ft}, \mathrm{E} / \mathrm{W}=27 \mathrm{ft} \\
1 \text { story }(8 \mathrm{ft})\end{array}$ \\
\hline Garage & None \\
\hline Neighbors & At $15 \mathrm{ft}, \mathrm{E} / \mathrm{W}$ \\
\hline Eave Depth & $2 \mathrm{ft}$ \\
\hline Vented Crawlspace & $2.0 \mathrm{ACH}, \mathrm{R}-19$ between joists \\
\hline Exterior Walls & $\begin{array}{l}2 \times 4,16 " \text { o.c., wood siding, } \\
\text { no cavity insulation (R-1.01 air gap) }\end{array}$ \\
\hline Unfinished Attic & $\begin{array}{l}2 \times 6 \text { joists, } \mathrm{R}-11 \text { insulation, } \\
3.5 \text { " thickness }\end{array}$ \\
\hline Window Type & $\begin{array}{l}\text { Single pane, } \\
\text { aluminum frame } \mathrm{w} / \text { thermal break, } \\
\text { National Fenestration Research } \\
\text { Council ratings for standard-size: } \\
\mathrm{U}=0.774 \mathrm{Btu} / \mathrm{hr}^{\mathrm{f}} \cdot \mathrm{ft}^{2} \cdot{ }^{\circ} \mathrm{F} \text {, } \\
\mathrm{SHGC}=0.679\end{array}$ \\
\hline Window Area/Distribution & $\begin{array}{l}20 \% \text { of exterior wall area, } \\
33.3 \% \text { of window area each on } \mathrm{N} / \mathrm{S} \text {, } \\
16.7 \% \text { of window area each on } \mathrm{E} / \mathrm{W}\end{array}$ \\
\hline Furnace & Electric \\
\hline Air Conditioner & SEER 10 \\
\hline Ducts & $\begin{array}{l}\text { Uninsulated, in crawl space, } \\
\text { leakage fraction }=0.30\end{array}$ \\
\hline Living Space SLA & Ratio $=0.000886$ \\
\hline Mechanical Ventilation & Spot vent only (bathroom, kitchen) \\
\hline Water Heater & $\begin{array}{l}\text { Electric, energy factor }=0.92, \\
\text { in living space }\end{array}$ \\
\hline Major Appliances & $\begin{array}{l}\text { Refrigerator, electric range, } \\
\text { dishwasher, clothes washer, } \\
\text { electric clothes dryer }\end{array}$ \\
\hline Thermostat Setpoints & Heating $68.0^{\circ} \mathrm{F}$, Cooling $78.0^{\circ} \mathrm{F}$ \\
\hline
\end{tabular}

\subsection{Assign Parameter Ranges}

To model uncertainty in audit-collected pre-retrofit data, probability distributions were assigned to building energy model input parameters. Inputs for which probability distributions were assigned are known as approximate inputs. Triangular probability distributions were used for this analysis, which are characterized by having greatest probability of selection at the "best-guess", or nominal, value with linearly decreasing probability to zero at the input range extrema $[11,13,16]$. An asymmetric triangular probability distribution is shown in Figure 1, where "Nominal" refers to the nominal ("best-guess") value, "Min" the minimum value, and "Max" the maximum value.

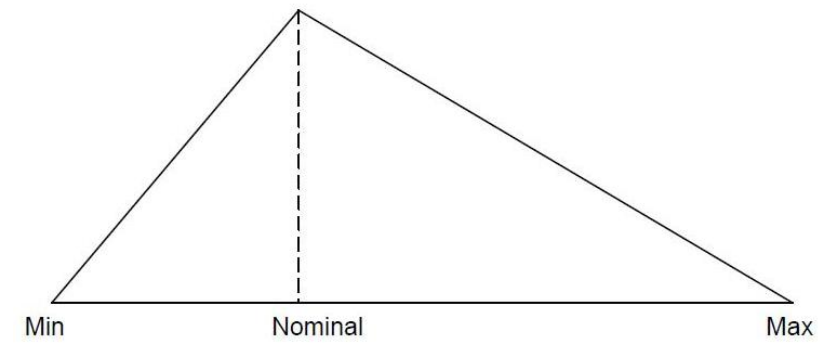

Figure 1: Triangular probability distribution.

The set of inputs with nominal values comprises the house's "uncalibrated" model. Some ranges were specified 
based on those found in BESTEST-EX and limits set forth in BPI Standard 2400 [17]. Other ranges were estimated using engineering judgment. Ranges can be found in Appendix A of Robertson et al. [18].

\subsection{Generate Synthetic Utility Data}

To obtain reference simulation results, explicit input values were first randomly selected from each of the triangular probability distributions. Explicit values were then substituted into the model's corresponding BEopt building description file, and the file was simulated in BEopt/DOE-2.2 for a time period of one year using Typical Meteorological Year 3 (TMY3) weather data for Las Vegas, NV.

The set of $n=12$ monthly total site electricity use predictions were extracted from the simulation output ${ }^{4}$ and became the "reference utility billing data" for model calibrations.

For this study, two utility billing data scenarios were considered by randomly generating multiple sets of reference utility billing data and then selecting two of the sets. One scenario had consistent overprediction (the uncalibrated model overpredicted reference billing data the entire season); this "overprediction" scenario was such that the uncalibrated model overpredicted the annual reference electricity consumption by $25.6 \%$. The second scenario had compensating errors (the uncalibrated model overpredicted reference heating energy but underpredicted reference cooling energy); this "underprediction" scenario was such that the uncalibrated model underpredicted the annual reference electricity consumption by $4.7 \%$. Investigating the two calibration methods in the context of multiple utility billing scenarios provides more information about the methods' strengths and limitations.

\subsection{Perform Calibration}

The next step of the self-testing procedure is to peform the input calibration procedures and recover "calibrated" models. In general, this involves applying adjustments to model input values until a desired level of agreement is achieved between simulation-predicted data and the reference utility data. Section 3 discusses the automated calibration procedures in detail.

\subsection{Assess the Benefit of Calibration}

Once the calibrated models have been recovered, various retrofit measures are applied to the uncalibrated, reference, and calibrated models. For this analysis, nine retrofit measures were applied:

1. Air-Seal;

2. Attic Insulation;

3. Wall Insulation;

4. Programmable Thermostat;

5. Low-e Windows;

6. Low Solar Absorptance Roof;

7. Duct Sealing and Insulation;

8. AC Replacement;

9. Combined ${ }^{5}$.

Descriptions of the retrofit measures can be found in Robertson et al. [18]. ${ }^{6}$ Once the retrofit measures have been applied to the pre-retrofit models, the post-retrofit annual results are labeled:

- $\psi_{r}$ for the reference model energy savings prediction,

- $\psi_{u}$ for the uncalibrated model energy savings prediction, and

- $\psi_{c}$ for the calibrated model energy savings prediction.

\footnotetext{
${ }^{4}$ This study considers only electric utility data since the modeled home consumes no other fuel type.

${ }^{5}$ This retrofit measure involves application of the previous eight retrofit measures.

${ }^{6}$ Unlike BESTEST-EX, the model considered in this study has space conditioning systems and so the additional measures \#7 and \#8, which were not featured in BESTEST-EX, were applied in this study.
} 
The absolute errors $\varepsilon\left(\psi_{c}\right)$ and $\varepsilon\left(\psi_{u}\right)$ are then calculated for the calibrated and uncalibrated model energy savings predictions using the equations

$$
\begin{aligned}
& \varepsilon\left(\psi_{c}\right)=\left|\psi_{c}-\psi_{r}\right|, \\
& \varepsilon\left(\psi_{u}\right)=\left|\psi_{u}-\psi_{r}\right|,
\end{aligned}
$$

and the benefit of calibration $(B o C)$ [13] is calculated using

$$
B o C=\varepsilon\left(\psi_{u}\right)-\varepsilon\left(\psi_{c}\right) .
$$

If $B o C>0$, then energy savings predicted using the calibrated model vs. the uncalibrated model are closer to the reference savings; in this situation, energy savings predictions are improved by calibration. The benefit of calibration $B o C$ has the same units as the energy savings predictions (kWh) and therefore can be compared across retrofit measures.

\section{Calibration Approach}

The two calibration approaches tested in this work each involve a procedure based on the general guidelines of ASHRAE 1051-RP:

Step 1. Define influential parameters;

Step 2. Perform a parametric sensitivity analysis on influential parameters to identify a subset of the most influential parameters; call these adjustable parameters ${ }^{7}$; and

Step 3. Using the adjustable parameters, apply a mathematical optimization (described in Section 3.2) to minimize the residuals between calibrated model utility data and reference utility data.

This study performs two applications of the ASHRAE 1051-RP-based procedure:

- Method A in which simulated annealing optimization is applied directly to BEopt/DOE-2.2 building simulations;

- Method B in which simulated annealing optimization is applied to response surface models which substitute BEopt/DOE-2.2 building simulations (same as Method A except for Step 3 modification).

Section 3.1 describes the statistical design of experiments, as well as the multiple linear regression (MLR) process used by Method B in producing the response surface models for predicting the home's energy use.

\subsection{Central Composite Design}

Central composite design and multiple linear regression allow us to efficiently sample from the adjustable parameter space, simulate these samples in BEopt/DOE-2.2, and use the predicted energy use "responses" to interpolate the samples and approximate predicted energy use for any sample within the adjustable parameter space. By using the simple approximation model instead of the detailed model, it is easier to perform the analysis since the computational effort is reduced [5].

Our central composite design implementation prescribes a total number of $2^{\tau}+2 \tau+1$ samples be simulated in BEopt/DOE-2.2, for $\tau$ the number of adjustable parameters considered. For this analysis $\tau=6$ adjustable parameters were considered $^{8}$, identified through the preliminary Monte Carlo sensitivity analysis, for a total of 77 BEopt/DOE-2.2 simulations. A design matrix $X$, whose rows of coded input values each correspond to a linearly-mapped BEopt/DOE2.2 simulation, is used with response matrix $Y$ (containing corresponding rows of monthly BEopt/DOE-2.2 simulation output) in a multiple linear regression. See Appendix A for more information on central composite design.

\footnotetext{
${ }^{7}$ This study uses a Monte Carlo procedure in which 100 random samples are made one-at-a-time from approximate input ranges, the samples are substituted into the house's pre-retrofit building description file, all files are simulated in automated batch mode, and "influence" is calculated as the coefficient of variation of the annual simulation output (the standard deviation divided by the mean).

${ }^{8}$ See Robertson et al. [18] (Section 3.1.2) for why $\tau=6$ was chosen as the number of adjustable parameters.
} 
Using ordinary least squares fitting, the multiple linear regression is performed by solving the system of normal equations using the unique $Q R$ factorization of $X$. This factorization is used to ensure numerical stability (see Trefethen and Bau, III [19]). The results are optimal regression coefficient $\beta_{0}$, linear regression coefficients $\beta_{1}, \ldots, \beta_{\tau}$, first-order interaction regression coefficients $\beta_{12}, \ldots, \beta_{\tau-1 \tau}$, and quadratic regression coefficients $\beta_{11}, \ldots, \beta_{\tau \tau}$ of the second-order polynomial functions

$$
\zeta_{k}\left(x_{1}, \ldots, x_{\tau}\right)=\beta_{0}+\sum_{i=1}^{\tau} \beta_{i} x_{i}+\sum_{i} \sum_{\substack{j \\ i<j}} \beta_{i j} x_{i} x_{j}+\sum_{i=1}^{\tau} \beta_{i i} x_{i}^{2},
$$

for $k=1, \ldots, n$, where $n$ is the number of data points used in the calibration (12 monthly points) and the $x_{i}$ are simulation input variables. The $\zeta_{k}$ regression models provide the best fit to each of the sets of monthly simulation data in the least-squares sense. Each $\zeta_{k}$ predicts energy use for month $k$. Using the response surface models significantly reduces the computational expense of predicting monthly energy use for the modeled house. On an Intel Core i7$3520 \mathrm{M}$ processor, each BEopt/DOE-2.2 simulation takes approximately five seconds to complete whereas annual predictions using the substitute models takes approximately two-hundredths of one second to complete.

\subsection{Simulated Annealing}

To reduce disagreement between simulation-predicted and reference utility data, an automated gradient-based simulated annealing optimization routine is applied. Simulated annealing inverts the calibration problem by iteratively adjusting the free model input values and minimizing corresponding objective function values (energy) until a prescribed number of iterations has been satisfied $[12,20]$. The calibration solution corresponding to the minimum calculated objective function value is the set of calibrated model inputs.

For this study our objective function, a weighted root mean square error, is defined to be the coefficient of variation of the root mean square error

$$
\mathrm{CV}(\mathrm{RMSE})=\frac{1}{\bar{y}} \sqrt{\frac{\sum_{i=1}^{n}\left(y_{i}-\hat{y}_{i}\right)^{2}}{n-1}} \times 100 \%
$$

where the $y_{i}$ are synthetic utility data, the $\hat{y}_{i}$ are simulation-predicted data, $\bar{y}$ is the synthetic utility data mean, and $n$ is the number of utility data points used in calibration [21].

Specifically, the steps for implementing the nonlinear optimization algorithm for the adjustable parameter search space are broken into two parts: (1) gradient calculations and (2) nonlinear iterative search. Sections 3.2.1 and 3.2.2 describe the components of these two parts, respectively.

\subsubsection{Gradient Calculations}

The first step in the simulated annealing algorithm uses multivariate analysis to randomly sample the adjustable parameter space. The information gained is used to determine how successive perturbations are generated and applied to the adjustable parameters during the iterative search. This Monte Carlo -type numerical integration technique identifies nonzero covariance between adjustable parameters. Gradients (i.e., changes in predicted energy use) are iteratively calculated for perturbations to random adjustable parameter space samples and then used to update a matrix storing this covariance information. After normalization of the covariance matrix by its trace, the principal components of the matrix are computed using an orthogonal linear transformation. The set of resulting components is orthogonal, each element of which is used as a multiplier for the iterative search portion of the algorithm [22]. Overall, this step preconditions the iterative search for improved efficiency.

\subsubsection{Iterative Search}

The second step in simulated annealing involves randomly perturbing the adjustable parameters, computing the change $\Delta E$ in successive objective function evaluations, deciding whether to accept perturbations resulting in positive $\Delta E$, and lowering the simulated annealing system temperature $T$ [22]. A crucial feature of this algorithm is its ability 
to escape from local minima within the parameter search space. The probability $P(\Delta E)$ that a perturbation results in an acceptable energy increase is defined by the commonly-used Boltzmann propability factor

$$
P(\Delta E)=\exp \left(\frac{-\Delta E}{T}\right)
$$

Thus, the algorithm is more likely to accept positive $\Delta E$ for large values of system temperature $T$. By iteratively descreasing system temperature $T$ according to the "fast simulated annealing cooling schedule", given by

$$
T=\frac{T_{0}}{N}
$$

where $T_{0}$ is the initial system temperature and $N$ is the current iteration, the algorithm seeks objective function value convergence while still permitting an expansive search within the adjustable parameter space [22, 23].

For both calibration Method A and Method B the automated optimization began at nominal values of the home's uncalibrated model. Each optimization was prescribed an initial system temperature $T_{0}=10$ and total number of function evaluations of 601 (one initial guess plus 100 evaluations per adjustable input).

For calibrating the home's building energy model using Method A, these steps were applied using the results of BEopt/DOE-2.2 simulations. That is, energy use predictions resulting from BEopt/DOE-2.2 simulations were used when evaluating the objective function during the search routine. However, for calibrating the home's building energy model using Method B, energy use predictions resulting from the response surface models were used when evaluating the objective function during the search routine.

\section{Results}

Graphical results for the iterative search portion of the simulated annealing optimization are shown in Figures 2 and 3. Here the parameter and residual convergence behavior can be seen as the search progresses. Results show more stable convergence for higher-influence parameters than lower-influence parameters (the figures order parameters by magnitude of influence coefficient). Figure 4 gives the results of the simulated annealing optimization in terms of the final calibrated input values. Accuracy of calibrated input values relative to reference values vary across adjustable parameters, calibration methods, and scenarios. 


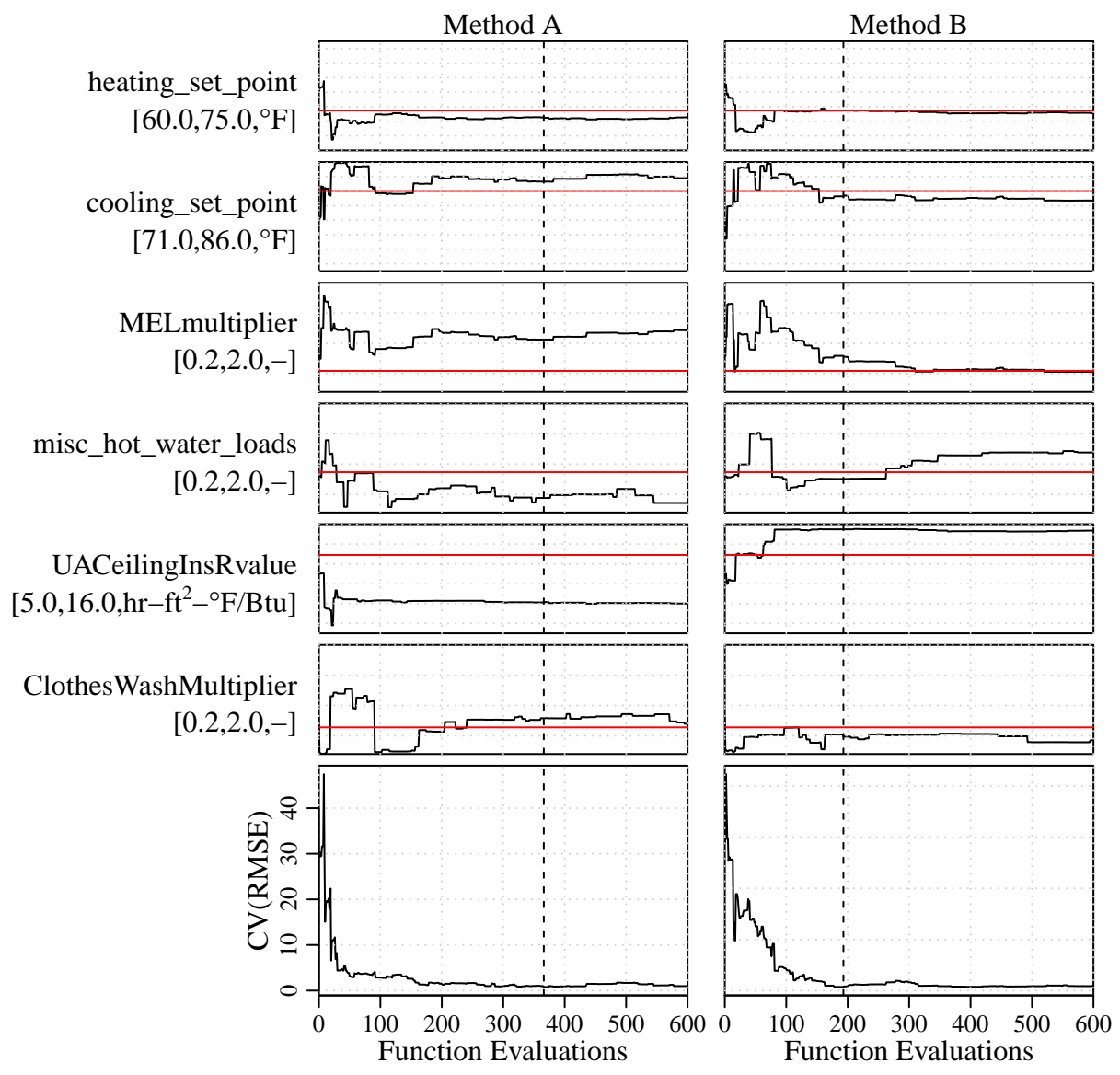

Figure 2: Convergence processes, overprediction scenario. Vertical dashed lines indicate calibration solution corresponding to lowest computed residual. Straight (red) horizontal lines are explicit reference input values. Included are range extrema and units of measure. 


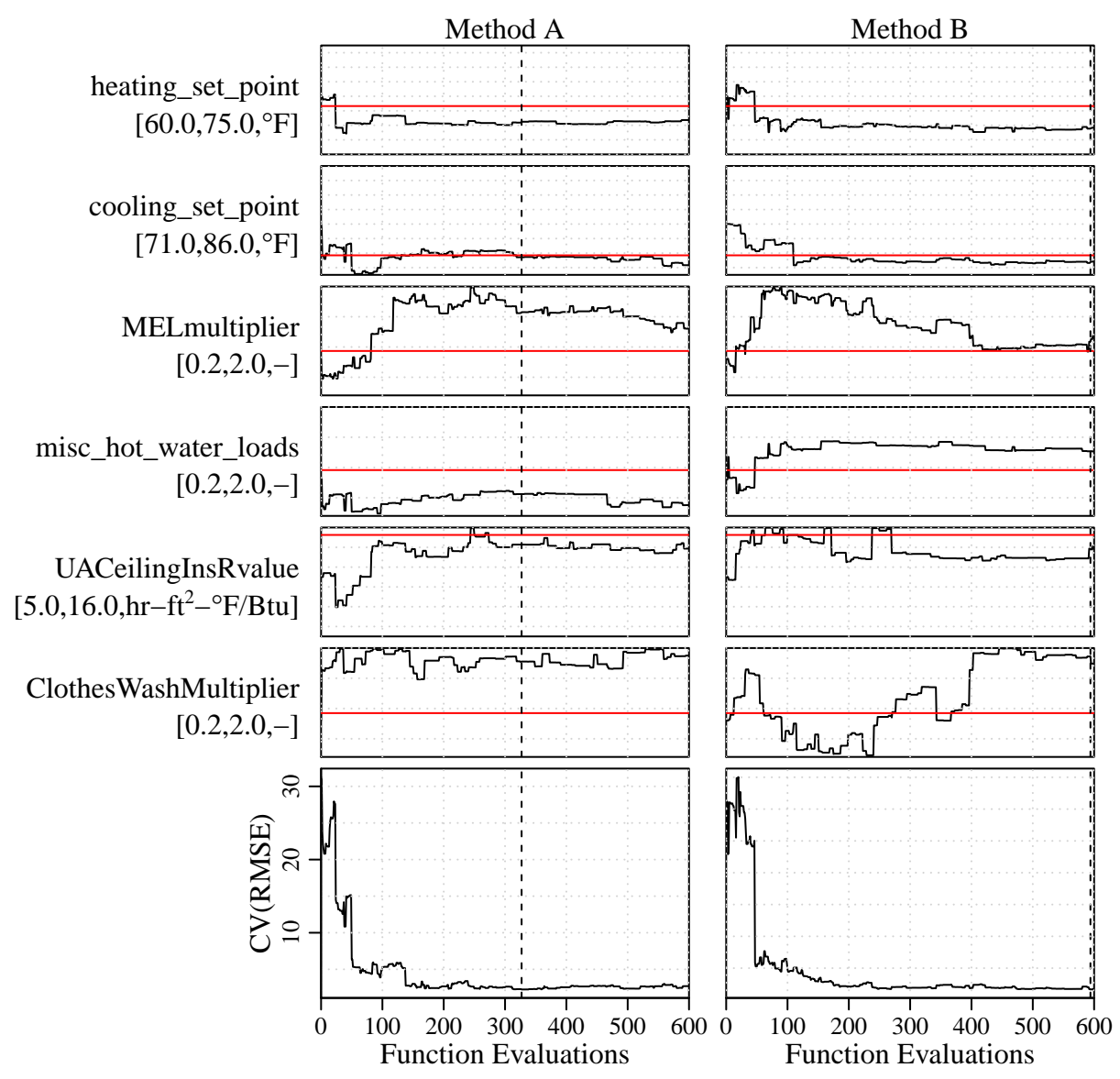

Figure 3: Convergence processes, underprediction scenario. Vertical dashed lines indicate calibration solution corresponding to lowest computed residual. Straight (red) horizontal lines are explicit reference input values. Included are range extrema and units of measure. 

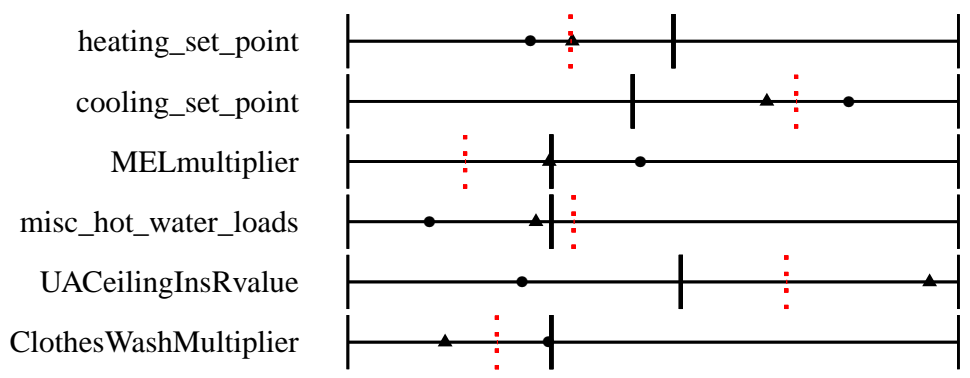

(a) Overprediction scenario.

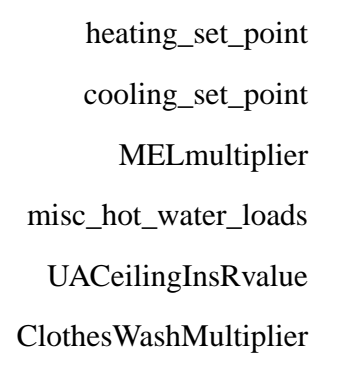

ClothesWashMultiplier

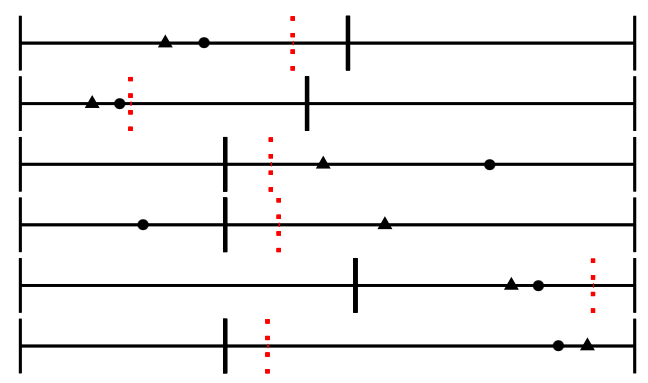

Reference

-.. Explicit

\section{Uncalibrated}

- Nominal

\section{Calibrated}

- Method A

- Method B
Reference

... Explicit

Uncalibrated

- Nominal

Calibrated

- Method A

- Method B

(b) Underprediction scenario.

Figure 4: Recovered input values from simulated annealing optimization. Left and right bounds represent the range extrema for input parameter values.

Retrofit measures listed in Section 2.5 were applied to the calibrated models recovered by Method A and Method B. Energy savings predicted using the uncalibrated and calibrated models were compared against reference energy savings. These results are shown in Figure 5 and demonstrate that calibrations using Method A and Method B tend to improve energy savings prediction accuracy for retrofit measures, although degree of improvement depends on utility bill scenario (i.e., how accurately the uncalibrated model can predict reference energy savings). 


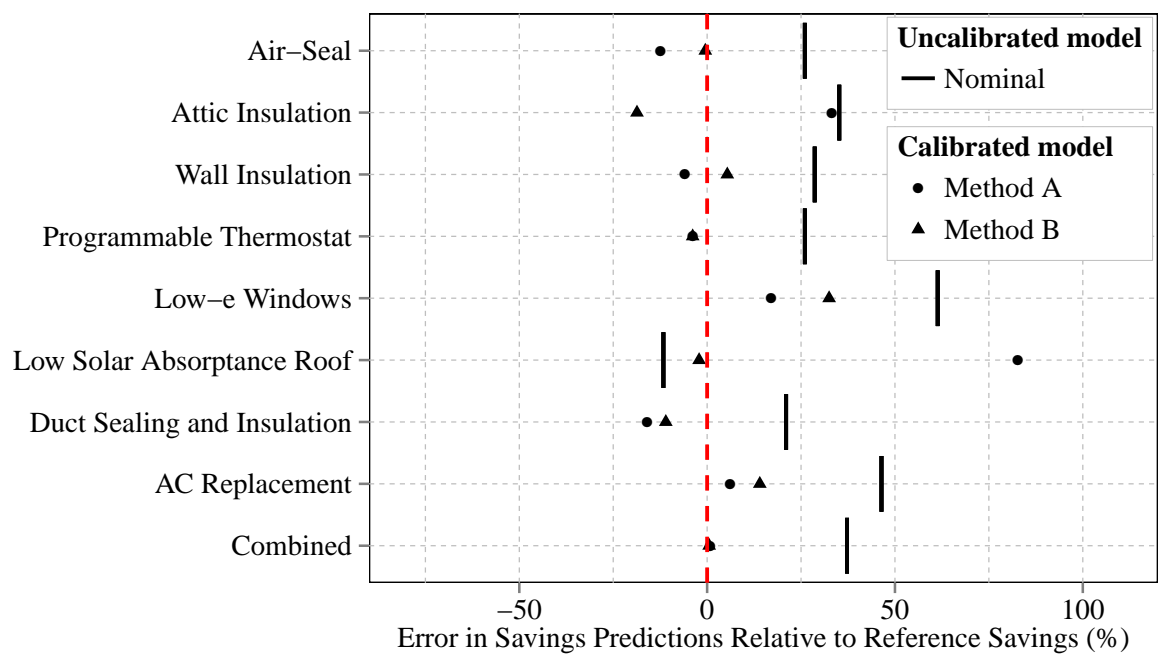

(a) Overprediction scenario.

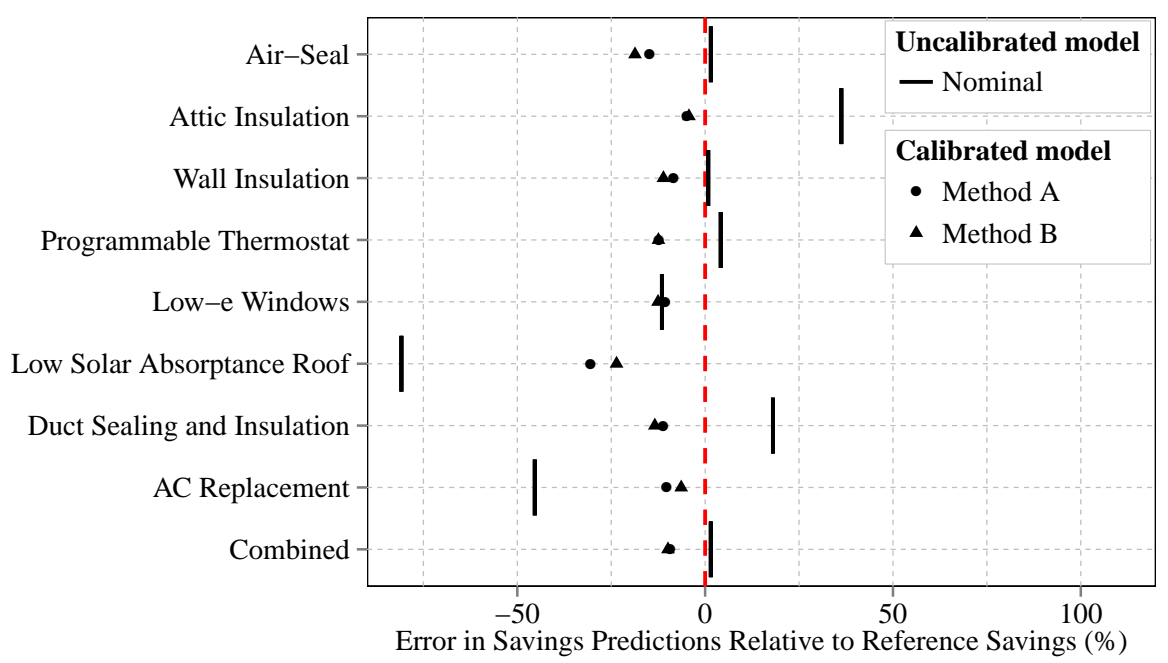

(b) Underprediction scenario.

Figure 5: Percent errors in predicted energy savings relative to reference energy savings. Vertical dashed line represents perfect agreement with reference energy savings.

The calibration methods were evaluated based on their ability to improve the accuracy of energy savings predictions for retrofit measures by tabulating and comparing the total benefit of calibration $T B o C$. Table 2 reports $T B o C$, which is calculated as the sum of the $B o C(\mathrm{kWh})$ across all retrofit measures listed in Section 2.5 (including the Combined retrofit measure).

\section{Discussion}

Table 3 gives a breakdown of computational cost by calibration method component; the table also shows calibration method equivalent computational costs when parallel computing resources are used. 
Table 2: Total Benefit of Calibration

\begin{tabular}{crr}
\hline & \multicolumn{2}{c}{$T B o C(\mathrm{kWh})$} \\
\cline { 2 - 3 } Method & Overprediction & Underprediction \\
\hline A & 6580.7 & 467.0 \\
B & 6915.3 & 277.4 \\
\hline
\end{tabular}

Table 3: Computational Cost

\begin{tabular}{clrr}
\hline Method & Component & Total simulations & Minimum series $^{\mathrm{b}}$ \\
\hline & Sensitivity analysis & 2400 & 1 \\
& Central composite design & N/A & N/A \\
& Gradient calculations & 350 & 1 \\
& Simulated annealing & 601 & 601 \\
& Retrofit measures & 9 & 1 \\
& Total & $\mathbf{3 3 6 0}$ & $\mathbf{6 0 4}$ \\
\hline & Sensitivity analysis & 2400 & 1 \\
& Central composite design & 77 & 1 \\
Gradient calculations & 0 & 0 \\
B & Simulated annealing & 0 & 1 \\
& Retrofit measures & 9 & $\mathbf{3}$ \\
\hline & Total & $\mathbf{2 4 8 6}$ & \\
\hline a Total number of BEopt/DOE-2.2 simulations. & & \\
b The equivalent computational time in terms of BEopt/DOE-2.2 simulations when \\
parallel computing is maximized (note: this does not include the computational time \\
that may be needed to initiate batch runs and process results).
\end{tabular}

Based on the implementations of the calibration methods and graphical and tabular results shown in Section 4 and Table 3, the following observations are made:

- Both Method A and Method B were entirely automated such that knowledge of reference results in no way influenced calibrated results;

- Based on total benefit of calibration $T B o C$, using both Method A and Method B improved the accuracy of energy savings predictions relative to reference energy savings for both calibration scenarios;

- In terms of $T B o C$, calibration provided more benefit for the overprediction scenario than the underprediction scenario;

- $T B o C$ is small for the underprediction scenario compared to the overprediction scenario, however calibration did reduce large discrepancies for individual measures in terms of percent error (e.g., Attic Insulation, Low Solar Absorptance Roof, AC Replacement);

- Calibration using Method B provided more benefit $(+335 \mathrm{kWh})$ than Method A for the overprediction scenario, but less benefit $(-190 \mathrm{kWh})$ for the underprediction scenario;

- Simulations within each component of Method B may be parallelized such that predicting energy savings using a calibrated model is cost-equivalent to only three BEopt/DOE-2.2 simulations in series.

For this study two automated calibration methods were implemented using BEopt/DOE-2.2 and tested using monthly synthetic utility billing data for scenarios in which the uncalibrated model overpredicts and underpredicts the reference utility billing data. The methods were able to adapt to the suggestions and guidelines from ASHRAE 1051-RP to residential building applications by showing both their effective use in improving energy use predictions for two sets of residential utility billing scenarios, as well as their ability to reduce overall simulation run-times. The two methods implemented used mathematical optimization; Method A used actual BEopt/DOE-2.2 simulations during the optimization whereas Method B used response surface models during the optimization. Various retrofit 
measures were applied to the models obtained using the calibration methods and the methods were evaluated based on accuracy of predicted energy savings and computational cost. The following section, Section 6, lists the primary conclusions to which this study led.

\section{Conclusions}

This study led to the following primary conclusions:

- The nonlinear simulated annealing algorithm provided a more computationally tractable and feasible avenue for residential building energy model calibration than a brute force approach would provide;

- For a prototypical existing residential building, Method A and Method B were effective in using the inversion algorithm to automate the model calibration process and improve the accuracy of energy savings predictions for retrofit measures;

- The prediction accuracy for Method B was on par with the more computationally-expensive Method A; in terms of $T B o C$, Method B slightly outperformed Method A for the overprediction scenario and Method A slightly outperformed Method B for the underprediction scenario;

- Method B can be dramatically streamlined using parallel-computing, thus making it an attractive option for calibration in residential applications; however, more scenarios are needed to evaluate and understand its performance across a range of conditions.

Overall, the results suggest that calibration methods similar to those described in this study could be implemented in residential simulation tools and tested in the field for automated calibrations to monthly utility billing data. They could be implemented within the context of emerging industry standards for residential model calibration (such as BPI Standard 2400 [17]). Software developers with the capability of running batch simulations in parallel (e.g., through cloud-computing) could employ methods similar to the response surface approach (Method B) to reduce the time required for automated calibration.

\section{Future}

This study was an initial step in investigating these automated residential calibration techniques in the context of monthly synthetic utility bill data. Further research is needed to evaluate residential calibration techniques in the following areas:

- More utility billing scenarios and house types;

- Calibration to sub-metered/disaggregated smart-meter utility data;

- Calibration to mixed-fuel utility data;

- Alternative optimization algorithms and objective functions;

- Validation using high-quality empirical data;

- Alternative sensitivity analyses and adjustable parameters;

- Evaluating retrofit options using multiple calibration solutions (as in ASHRAE 1051-RP).

\section{Acknowledgement}

This work was in part supported by the Alliance Partner University Program between the National Renewable Energy Laboratory (NREL) and the Colorado School of Mines, Grant No. UGA-0-41025-12. The authors wish to thank the U.S. Department of Energy Building Technologies Program and David Lee (U.S. Department of Energy Team Leader, Residential Buildings) for their continued support. 


\section{Appendix A. Central Composite Design}

The central composite design matrix $X$ relies on a 2-level full factorial, axial points, and center run vertically concatenated design composite. Axial points are calculated by

$$
\omega=2^{-\frac{\tau}{4}}
$$

where $\tau$ is the number of parameters considered in the design $(\tau=6$ in this work). Each row of the submatrix whose columns are the $2^{\text {nd }}$ through the $(\tau+1)^{\text {th }}$ columns of $X$ are coded realizations (corresponding to the $1^{\text {st }}$ through $\tau^{\text {th }}$ parameter) which, when replaced in the pre-retrofit building description file and simulated in BEopt/DOE-2.2, produce a response matrix $Y$ whose dimensions are $\left(2^{\tau}+2 \tau+1\right) \times n$, where $n$ is the number of data points to which the calibrations are performed ( $n=12$ monthly data points for this analysis). The coded values $X_{i, j}$ linearly map to input values $X_{i, j}^{\prime}$ by

$$
X_{i, j}^{\prime}=X_{i, j}\left(\frac{1}{2}\left(x_{j}^{\max }-x_{j}^{\min }\right)\right)+\left(\frac{1}{2}\left(x_{j}^{\max }+x_{j}^{\min }\right)\right)
$$

for $j=1, \ldots, \tau$, where the $X_{i, j}$ are elements from coded realizations submatrix of $X$, and $x_{j}^{\min }$ and $x_{j}^{\max }$ are the minimum and maximum values, respectively, of the probability distribution for the $j^{\text {th }}$ adjustable input. There exist alternative designs for constructing second-order metamodels for use in response surface methodology. For this analysis, the central composite design was chosen and implemented due to its low cost, widespread use, and ability to capture second-order effects produced by BEopt/DOE-2.2 simulations [24-29].

\section{References}

[1] Kissock JK, Haberl JS, Claridge DE. Inverse Modeling Toolkit (1050-RP): Numerical Algorithms for Best-Fit Variable-Base Degree-Day and Change-Point Models. ASHRAE Trans 2003;109(2):425-34.

[2] Lee SU, Claridge DE. Automatic calibration of a building energy simulation model using a global optimization program. In: Proceedings of the Second International Conference for Enhanced Building Operations. Richardson, TX, 2002; 2002,.

[3] New J, Sanyal J, Bhandari MS, Shrestha SS. Autotune E+ building energy models. In: Proceedings of the Fifth National SimBuild of IBPSA-USA. 2012

[4] K. Greely, Performance Systems Development . Increasing accuracy of modeled savings through utility bill calibration. http:// acinational.org/sites/default/files/session/81124/aci11eval8greeelykathy.pdf; 2011

[5] Manfren M, Aste N, Moshksar R. Calibration and uncertainty analysis for computer models - A meta-model based approach for integrated building energy simulation. Appl Energ 2013;103:627-41.

[6] Eisenhower B, O’Neill Z, Narayanan S, Fonoberov VA, Mezic I. A methodology for meta-model based optimization in building energy models. Energ Buildings 2012;47:292-301.

[7] Heo Y, Choudhary R, Augenbroe GA. Calibration of building energy models for retrofit analysis under uncertainty. Energ Buildings 2012;47:550-60.

[8] Sanyal J, New J, Edwards RE, Parker L. Calibrating building energy models using supercomputer trained machine learning agents. Concurr Comp-Pract - E 2014;26:2122-33.

[9] Im P, Bhandari M. Is monthly and whole building level calibration enough?: A detailed modeling and calibration study of an ultra-efficient occupancy simulated house. In: ASHRAE/IPBSA-USA Building Simulation Conference. 2014, p. 177-86.

[10] Edwards RR, New JR, Parker LE. Estimating building simulation parameters via bayesian structure learning. In: Proceedings of the 2nd International Workshop on Big Data, Streams and Heterogeneous Source Mining: Algorithms, Systems, Programming Models and Applications. 2013, p. 31-8.

[11] Reddy TA, Maor I. Procedures for Reconciling Computer-Calculated Results With Measured Energy Data, ASHRAE Research Project 1051-RP. American Society of Heating, Refrigerating and Air-Conditioning Engineers, Inc.; Atlanta, GA; 2006.

[12] Kirkpatrick S, Gelatt CD, Vecchi MP. Optimization by simulated annealing. Science 1983;220(4598):671-80.

[13] Judkoff R, Polly B, Bianchi M, Neymark J. Building Energy Simulation Test for Existing Homes (BESTEST-EX); Phase 1 Test Procedure: Building Thermal Fabric Cases. Tech. Rep. TP-550-47427; National Renewable Energy Laboratory; Golden, CO; 2010.

[14] Judkoff R, Polly B, Bianchi M, Neymark J, Kennedy M. Building Energy Simulation Test for Existing Homes (BESTEST-EX): Instructions for Implementing the Test Procedure, Calibration Test Reference Results, and Example Acceptance-Range Criteria. Tech. Rep. TP-550052414; National Renewable Energy Laboratory; Golden, CO; 2011.

[15] Christensen C, Anderson R, Horowitz S, Courtney A, Spencer J. BEopt Software for Building Energy Optimization: Features and Capabilities. Tech. Rep. TP-550-39929; National Renewable Energy Laboratory; Golden, CO; 2006.

[16] Kotz S, van Dorp JR. Beyond Beta, Other Continuous Families of Distributions with Bounded Support and Applications. Singapore: World Scientific Publishing Co.; 2004.

[17] BPI-2400-S-2011: Standardized Qualification of Whole House Energy Savings Estimates. Building Performance Institute, Inc.; 2011.

[18] Robertson J, Polly B, Collis J. Evaluation of Automated Model Calibration Techniques for Residential Building Energy Simulation. Tech. Rep. TP-5500-54084; National Renewable Energy Laboratory; Golden, CO; 2013. 
[19] Trefethen LN, Bau, III D. Numerical Linear Algebra. Philadelphia, PA: Society for Industrial and Applied Mathematics; 1997.

[20] Kuperman WA, Collins MD, Perkins JS, Davis NR. Optimal time-domain beamforming with simulated annealing including application of a priori information. J Acoust Soc Am 1990;88(4):1802-10.

4 [21] Guideline 14-2002: Measurement of Energy and Demand Savings. American Society of Heating, Refrigerating and Air-Conditioning Engineers, Inc.; Atlanta, GA; 2002.

[22] Collins MD, Kuperman WA, Schmidt H. Nonlinear inversion for ocean-bottom properties. J Acoust Soc Am 1992;92(5):2770-83.

[23] Szu H, Hartley R. Fast simulated annealing. Phys Lett A 1987;122(3,4):157-62.

[24] Barton RR. Simulation optimization using metamodels. In: Rossetti MD, Hill RR, Johansson B, Dunkin A, Ingalls RG, editors. Proceedings of the 2009 Winter Simulation Conference. 2009, p. 230-8.

[25] Batmaz I, Tunali S. Second-order experimental designs for simulation metamodeling. Simulation 2002;78(12):699-715.

[26] Chlela F, Husaunndee A, Inard C, Riederer P. A new methodology for the design of low energy buildings. Energ Buildings 2009;41:982-90.

[27] Snyder SC, Reddy TA, Addison MS. Automated design of buildings: Need, conceptual approach, and illustrative example. In: American Society of Heating, Refrigerating and Air-Conditioning Engineers, Inc. AHR Expo. 2013,

[28] Durieux S, Pierreval H. Regression metamodeling for the design of automated manufacturing system composed of parallel machines sharing a material handling resource. Int J Prod Econ 2004;89:21-30.

[29] Kleijnen JPC, Sargent RG. A methodology for fitting and validating metamodels in simulation. Eur J of Oper Res 2000;120:14-29. 